\title{
Психокорекція мовних розладів у дітей, що страждають на дитячий церебральний параліч
}

Анотація. В статті представлена характеристика локально обмежених ушкоджень (ЛОУ) головного мозку дитини, які здійснюють вирішальний - негативний вплив на природні процеси формування і розвитку у дитини вищих психічних функиій, зокрема у дітей, які страждають на дитячий церебральний параліч (ДЦП). Розглядаються і пропонуються методики комплексної реабілітації цього контингенту дітей, засновані на використанні узгодженої і адаптованої невролого-психологічної і психолого-педагогічної роботи.

Дається характеристика мовленнєвих розладів і їх типів, а також опис діагностичних досліджень та напрямків психокорекиійної роботи з дітьми, хворими на ДЦП.

Ключові слова: головний мозок, вищі психічні функиї̈, локально-органічні ураження головного мозку, психокорекиія, компенсаторні механізми.

Известно, что локально-органические поражения (ЛОП) головного мозга ребёнка в пре- и постнатальный периоды его развития оказывают выраженные негативные влияния на естественные процессы формирования и развития у него высших психических функций и психики в целом. Причём, являясь первопричиной или первичным дефектом, ЛОП неизменно порождают в ходе последующего аномального развития головного мозга ребёнка, его центральной нервной системы (ЦНС) и психики вторичные нарушения, вторичные дефекты, характеризующиеся недоразвитием или патологическим формированием и развитием высших психических функций, таких как речь, память, сознание, воля, интеллект, внимание и многих других. Приводят к нарушению у ребёнка познавательных процессов, особенно ярко проявляющих себя в ходе его последующего социального развития и становления как личности.

Вместе с тем, следует особо выделить и подчеркнуть, что в целом негативное влияние ЛОП на общий процесс развития ЦНС и высших психических функций служит невольным, но активным источником включения у ребёнка значительных компенсаторных механизмов, заложенных у него как в морфологической избыточности структур головного мозга, так и в их высокой пластичности. В результате, как следствие, именно эти положительные тенденции в функциональной деятельности мозга, позитивно проявляющие себя в общем патологическом процессе формирования и развития высших психических функций у ребёнка, служат тем исходным материалом и тем надёжным фундаментом, благодаря которому головной мозг ребёнка оказывается способным не только компенсировать влияние первичного дефекта, но и при своевременной и чётко выверенной психолого-педагогической корректировочной работе с ним включить механизмы компенсации функций анализаторных систем мозга, обеспечить развитие тех его структур, деятельность которых была нарушена патологическим процессом и, тем самым, заторможена в своём развитии деструктивным влиянием ЛОП.

Именно последние, на наш взгляд, как раз и будут реально способствовать развитию в пластичном мозге ребёнка как процессов формирования новых функциональных связей и путей, так и не менее активно содействовать оптимальному использованию сохранных.

При этом абсолютно не исключено, что именно эти положительные структурные и функциональные изменения во вторичном дефекте, позволят, в свою очередь, и существенно понизить степень влияния первичного дефекта на общее состояние ЦНС ребёнка, и активно способс- 
твовать процессам формирования и развития у него высших психических функций.

Принимая во внимание, что современная клиника церебрального паралича располагает большим арсеналом современных технических средств, использование которых позволяет установить топику поражения головного мозга; оценить степень сохранности двигательного, зрительного, слухового, кожно-кинестетического и других анализаторных систем; выявить те негативные факторы, оказывающие непосредственное влияние на процессы патологического формирования таких сложных форм психической деятельности как речь, память, восприятие, интеллектуальные процессы и многое другое.

Вместе с тем, и это также следует признать, что современные методы диагностики, равно как и те устройства, благодаря которым они реализуются, далеко не всегда позволяют достоверно определить зрелость и функциональную сохранность как отдельных нейронов, так и образованных ими вполне конкретных структур и функциональных систем, но и главное, достоверно определить их готовность и реальные функциональные возможности к пластичному замещению патологически изменённых мозговых структур функционально сохранными.

Наметить пути и определить как методы, так и время и этапность в формировании и развитии у ребёнка структур головного мозга и, соответственно, его высших психических функций, начиная от постнатального периода его жизни. Поэтому следующим шагом в общей для неврологии и психологии проблеме комплексной реабилитации детей, страдающих церебральным параличом, формировании и развитии у них высших психических функций: речи, памяти, восприятия, интеллекта, - могут стать адаптационно сочетанные, взаимодополняющие формы и неврологической, и психологической форм клиникодиагностической и психолого-педагогической работы.

Так, психологический подход, как к дефекту, так и к методам его преодоления, позволит раскрыть сущность дефекта, его психологическую структуру и, тем самым, получить ответ на следующие вопросы: что нужно сделать для устранения дефекта или, как минимум, уменьшения его влияния на функционально взаимосвязанные с ним структуры. Например, какие сохранные психические функции необходимо включить в систему воздействия на дефект, какие уровни организации речи и какую её форму наиболее целесообразно развивать у ребёнка при данном - вполне конкретном ЛОП его мозга.

В свою очередь, современная нейропсихология, соотнося представления о структуре и характере психических процессов с данными о состоянии конкретных отделов и структур головного мозга их продуцирующих, позволит нам применить находки и достижения психофизиологии для разработки новых, наиболее рациональных методов и приёмов целевого воздействия на мозг с целью восстановления и развития у ребёнка тех высших психических функций, деятельность которых затормаживалась или даже угнеталась прилежащими патологически изменёнными структурами.

И, наконец, педагогический подход, учитывая вскрытые механизмы дефекта, его психологическую структуру и непосредственную взаимосвязь с другими психическими функциями, позволит нам установить и наиболее точный, и единственно верный путь к организации собственно учебного процесса, благодаря которому ребёнок сможет преодолеть имеющийся у него речевой дефект.

Из сказанного выше, совершенно очевидным становится тот факт, что все выше перечисленные клинические и психологопедагогические подходы и методы комплексной реабилитации детей, страдающих церебральным параличом, должны находиться в тесном единстве и взаимодействии. Один, пусть даже широко распространённый неврологический подход, мало что даёт ребёнку в плане формирования и развития у него высших психических функций, как, впрочем, и изолирован- 
ные психологический или педагогический подходы.

Вместе же, структурно и функционально дополняя друг друга, они будут служить тем надёжным фундаментом и тем эффективным средством блокирования ЛОП, благодаря которым неизбежные функциональные перестройки в деятельности головного мозга, обеспечат ему условия для его восстановления и, тем самым, нормального функционирования высших психических функций.

Современная психология, нейропсихология, психофизиология и педагогика располагают большим объёмом научных исследований и практических наработок по классификации речевых расстройств, формам и методам восстановления речи у больных с ЛОП мозга при всех формах афазии. В то же время, аналогичных исследований по глубине и полноте изучения проблемы, обоснованию форм и методов формирования и развития высших психических функций у детей с ЛОП мозга, начиная с постнатального периода их развития, классификации речевых расстройств и психолого-педагогически обоснованных сроков и методов функциональной компенсации вторичного дефекта и обучения ребёнка речи, практически не существует.

Вместе с тем, проблема в целом не стоит на месте. Благодаря общей тенденции в изучении структурной организации мозга, механизмов его функционирования в норме и при различных видах патологии, а также благодаря успешному развитию новых клинических областей применения нейропсихологии и психофизиологии, таких как нейрохирургия и стереотаксис глубоких структур мозга (Смирнов В.М., 1976 , Кузьмина Т.В. в соавт., 1981), неврология и нейрохирургия детского возраста (Симерницкая Э. Г., 1981), дефектология (Марковская И. Ф., Лебединский В. В., Лебединская К.С., 1981, Астапов В.М., 1994), психиатрия (Балонов Л. Я. и Деглин В.Л., 1976 и др.), эндовазальная нейрохирургия (Московичюте Л.И., 1978 и др.) в сочетании с теорией и практикой восстановления речи у больных с различными формами афазии, разработанных А.Р. Лурией, его учениками и последователями, внесшими существенный вклад в понимание мозговых механизмов сложных психических функций и путей преодоления патологических состояний.

Однако следует признать, что результаты выше названных исследований могут служить в настоящее время лишь отправной - методологической и научной базой в системном анализе первичного и вторичного дефектов у детей, страдающих церебральным параличом. Начиная с постановки топического диагноза и прогноза функциональной готовности головного мозга ребёнка к формированию и развитию высших психических функций и заканчивая обоснованием сроков, форм, методов и этапов психолого-педагогического обучения мозга на основе современных представлений о высших психических функциях и их системной организации.

Многочисленные исследования процессов формирования высших психических функций у нормально развивающихся детей показывают, что существуют особые возрастные периоды, в которые обучающие воздействия оказывают наибольшее влияние на ход их психического развития. Такие периоды называют «сензитивными периодами развития». У ребёнка сензитивный период развития речи наступает, как правило, в возрасте от 1,5 до 3-х лет. Причём, формируясь у ребёнка по мере овладения языком, речь проходит несколько этапов развития, превращаясь в развернутую систему средств общения и опосредования различных психических процессов. В качестве двух основных самостоятельных видов речи современная психология выделяет экспрессивную и импрессивную речь, которые характеризуются различным психологическим строением.

Экспрессивная речь - это высказывание с помощью языка, которое начинается с замысла (программы), затем переходит стадию внутренней речи и только после этого переходит в стадию развернутого речевого высказывания в форме устной речи или письма. 
Импрессивная речь - это процесс понимания речевого высказывания (устного или письменного), который начинается с восприятия речевого сообщения посредством слуха или зрения, проходит стадию выделения информационных моментов и завершается формированием во внутренней речи общей смысловой схемы сообщения и его понимания.

С точки зрения лингвистики в речи выделяют следующие единицы:

- фонемы (смыслоразличительные звуки речи);

- лексемы (слова или фразеологические словосочетания);

- семантические единицы (обобщения в виде системы слов, обозначающих понятия);

- предложения (сочетания слов, отражающих вполне зрелую, достаточно продуманную и чётко выраженную мысль);

- высказывания (законченные сообщения).

Причём каждая из четырёх самостоятельных форм речи включает в себя несколько речевых функций. Устная речь может быть монологической и диалогической. Письменная речь - самостоятельной или под диктовку.

В целом же каждая из выше названных речевых функций имеет различное психологическое строение. Однако в целом, собственно речевая система человека представляет собой совокупность речевых функций, объединённых в единую функциональную систему, обладающую многими характеристиками, отличающими её от других систем. Сложность речевой системы обусловлена ещё и тем, что каждая из четырёх входящих в неё подсистем имеет свою - вполне определённую - чётко выраженную автономность и различные сроки формирования и развития. И если в школьном возрасте у нормально развивающегося ребёнка органическое и функциональное созревание речевых систем в основном уже закончено, то у детей, страдающих церебральным параличом, сензитивный период характеризуется, в от- личие от нормы, наибольшей уязвимостью и даже явлениями регресса.

Поэтому процесс формирования у детей, страдающих церебральным параличом, высших психических функций будет являть собою конгломерат, состоящий из сохранных, повреждённых и в разной степени задержавшихся в своём развитии высших психических функций. В этом случае, по мнению В.В. Лебединского (1985), нарушение процесса формирования высших психических функций у детей с локально органическими поражениями головного мозга может быть представлен следующими вариантами:

- недоразвитием;

- задержкой развития;

- поврежденным развитием;

- дефицитарным развитием;

- искаженным развитием;

- дисгармоническим развитием.

Вместе с тем, характер аномального развития у ребёнка высших психических функций зависит также и от того, когда возникло повреждение мозга. Чем раньше произошло повреждение, тем вероятнее явления недоразвития. Причём в этом случае временной фактор определяется не только хронологическим моментом возникновения нарушения, но и длительностью развития функции в онтогенезе. Чаще повреждаются функции, имеющие подкорковую локализацию, формирование которых в онтогенезе завершается относительно рано. Корковые же функции, имеющие более длительный период развития, при раннем воздействии вредности чаще всего либо стойко не развиваются, либо временно задерживаются в своем развитии. Именно поэтому у детей с церебральным параличом, как правило, трудно выделить симптоматику речедвигательных расстройств вследствие сложности поражения головного мозга и нарушения процесса формирования и развития речи. Поэтому обследование ребёнка и выявление у него нарушений развития речи проводится, как правило, в двух основных направлениях:

- Фонетико-неврологическом; 
- Психолого-лингвистическом.

При фонетико-неврологическом обследовании логопед совместно с невропатологом и психологом анализирует состояние подвижности речевых мышц, возможность выполнения артикуляционных позиций, состояние ритмико-методических свойств речи, особенности звукопроизношения, определяется форма клинического речедвигательного синдрома, уровень локализации поражения ЦНС. Суть этого обследования сводится к получению, а затем и к анализу следующей данных:

1. Произносительной стороны речи в условиях спонтанной речевой активности ребёнка и при произвольных его усилиях в ответ на просьбу логопеда и (или) невропатолога и (или) психолога:

- голос: его сила, высота, продолжительность, модулированность;

- темп, ритм речи;

- интонация речи;

- звукопроизношение: пропуск, замена, искажение звуков;

- разборчивость общая (оценивается понимание речи ребёнка в зависимости от коммуникативного расстояния и от качества предварительного знания контекста);

- выразительность речи.

2. Мышцы речевого аппарата (особенности движений мышц во время речи и в процессе выполнения специальных заданий):

- сила мышц;

- подвижность;

- амплитуда, объём движений;

- симметричность включения в движение;

- точность и соразмеренность в выполнении движений;

- скорость переключения движений;

- латентный период при включении в движение.

3. Характер произношения звуков и возможность воспроизведения звуков проверяются в специальных слоговых заданиях (прямые, закрытые, обратные слоги и слоги со стечением согласных).
Звуки оцениваются по месту и способу их образования:

- смычные твёрдые и мягкие, глухие и звонкие;

- щелевые твёрдые и мягкие, глухие и звонкие;

- аффикативные;

- сонорные твёрдые и мягкие;

- гласные.

4. Характер произношения слогов: прямых, обратных, закрытых, со стечением согласных.

5. Вегетативные реакции во время речи: покраснение, бледность, потоотделение, слюнотечение.

По окончанию обследования логопедом совместно с невропатологом и психологом составляется, например, такое заключение:

1. Форма дизартрии (определяется на основании ведущего речедвигательного синдрома).

2. Форма звукового расстройства речи:

- I форма - искажения;

- II форма - пропуски, замены;

- III форма - слоговые нарушения.

При психолого-лингвистическом обследовании ребенка, как правило, анализируются уровень его фонематического восприятия, речевого слуха, речевого контроля за своей речью, уровень мотивации к общению, особенности речевой коммуникации, использование и понимание лексических и грамматических средств языка.

Обращает на себя внимание и фактически полное отсутствие классификации речевых расстройств, основанных на принципе вычленения механизмов и факторов, которые лежат в основе нарушений в развитии функциональной системы, обеспечивающей как речь, так и синдромный анализ нарушений, влияющих на процесс её формирования.

Как следствие процесс формирования и развития высших психических функций у детей, страдающий церебральным параличом, осуществляется лишь в рамках общего контекста двигательных нарушений. При этом выделяются, как правило, следующие основные синдромальные 
расстройства: спастический парез, ригидность, гиперкинезы и апраксии.

Такой подход к анализу нарушений, препятствующих формированию и развитию речевой деятельности у ребёнка неоправданно упрощает сложный и многогранный процесс развития у него речевой функциональной системы, в формировании которой принимают участие все анализаторы: слуховой, зрительный, кожно-кинестетический и двигательный. Причём, каждый из них вносит свой вклад в афферентные и эфферентные основы процесса формирования и развития у ребёнка речи.

В результате анализ на основе той или иной патологии моторной стороны речевой деятельности сводит классификацию речевого недоразвития или патологического её формирования и развития лишь к одной из форм речи - экспрессивной. И то не для всех её стадий, а лишь по отношению к последней: стадии развернутого внешнего речевого высказывания в форме устной речи.

Соответственно этому подходу к классификации, моторные нарушения речи различают в форме различных дизартрий, дислалий и заикания. Из перечисленных форм нарушения процесса развития речи, к наиболее сложной и тяжелой форме относится дизартрия, т.к. структура её неоднородна и не исчерпывается проявлением лишь псевдобульбарного синдрома. При дизартрии страдает не только произношение, но и темп, выразительность, модуляция. Общими клиническими признаками дизартрии являются нарушения мышечного тонуса в артикуляционной мускулатуре и, в частности, их подвижность в результате параличей и парезов. При тяжелой степени дизартрии - анатрии, полностью отсутствует произносительная сторона речи.

Существует несколько видов дизартрии:

- псевдобульбарная дизартрия, которая характеризуется повышенным мышечным тонусом, ограниченностью движений губ, языка, слюнотечением. При этом речь смазанная и голос немодулированный;
- бульбарная дизартрия, при которой к вышеописанным особенностям добавляется выраженная атрофия мышц языка и глотки;

- подкорковая дизартрия характеризуется непроизвольно меняющимся мышечным тонусом в артикуляционной мускулатуре;

- мозжечковая дизартрия характеризуется выраженной асинхронностью артикуляции, голосообразования и дыхания, нарушением темпа и плавности речи.

Следует также особо выделить и подчеркнуть, что моторные нарушения речи сказываются не столько на чисто исполнительной стороне речедвигательной системы ребёнка, сколько на её программирующей и регулирующей функциях.

В свою очередь, нарушения исполнительного характера как правило, проявляют себя в форме спастического пареза артикуляционных мышц, тонических нарушений по типу регидности, гиперкинезов, атаксии, а также в форме смешанных синдромов: спастико-ригидных, спастикогиперкинетических, спастико-атаксических и других комбинациях.

Нарушения программирующего характера проявляют себя дефектами формирования кинестетического анализа и синтеза артикулярных движений, которые ограничивают возможности ребёнка в воспроизведении нужных звуков речи. Это особенно заметно при наличии у ребёнка частичной артикуляторной апраксии, дизартрии и апраксических аллалий.

Нарушения регулирующего характера в речедвигательной системе ребёнка проявляют себя расстройствами речи типа заикания и нарушениями в механизмах контроля, обеспечивающих фонематический анализ звуков речи.

Качество же собственно звуковых расстройств у детей с различными формами дизартрий далеко неодинаково: звуки не только могут быть искажены, но и фонетически противопоставлены - это первая форма звукового расстройства; звуки заменяются или пропускаются, хотя 
в целом слоговая структура слова остается без изменений — это вторая форма; когда же звуки заменяются, пропускаются или искажаются при произношении, а также сопровождаются негрубыми дефектами слоговой структуры слова - это третья форма звукового расстройства.

В целом же все виды расстройств речи тяжело сказываются на развитии у ребёнка высших психических функций. Однако как бы ни были сложны чисто дизартрические расстройства речи, не они оказывают выраженное тормозящее влияние на развитие у ребёнка психики и высших психических функций.

Наиболее резко снижают процесс формирования и развития высших психических функций речедвигательные механизмы речи, непосредственно влияющие на собственно лингвистическую - языковую систему. Как следствие речедвигательных механизмов речи у ребёнка не формируется понимание и использование лексических и грамматических структур, и, следовательно, не формируются, и не развиваются мыслительные навыки.

Эти нарушения речи наиболее выражено проявляют себя в форме различных алалий: сенсорных, сенсомоторных, моторных, семантических и динамических. В результате речевое мышление у ребёнка (стадия замысла или программы, стадия внутренней речи) формируется замедленно и неполноценно во все возрастные периоды его развития.

Общее речевое недоразвитие (или так называемые аллалические расстройства) у детей, страдающих церебральным параличом, как правило, либо сочетаются с дизартрическими нарушениями, либо же проявляют себя в качестве самостоятельного дефекта. Кроме того, специфические речевые дефекты проявляются у детей c нарушениями формирования процесса осознания языковых звуков, особыми трудностями в понимании смысловых отношений, скрытых за лексико-синтаксическими связями.

В целом же принимая во внимание, что многообразие форм речевых расстройств и сложность их преодоления, как правило, обусловлены необратимыми органическими поражениями головного мозга ребёнка и, в частности, его двигательного анализатора, произошедшими либо в период его внутриутробного формирования и развития, либо вследствие черепно-мозговой травмы уже в ходе собственно родового процесса. В любом случае методы реабилитации этого контингента детей, основанные не на непосредственном устранении дефекта, либо на существенном снижении его влияния на прилежащие - сохранные структуры мозга, оказываются явно недостаточными. Как показывает практика реабилитации речевых и двигательных расстройств у детей, страдающих ДЦП, наиболее эффективными оказываются методы сочетанного - целенаправленного влияния на структуры головного мозга ребёнка рядом физиотерапевтических факторов в сочетании с логопедическими методиками и целенаправленными развивающими физическими упражнениями (Серёгин Ю.В. Способ лечения детских церебральных параличей и устройство для его осуществления).

\section{Список використаних джерел:}

1. Смирнов В.М. Неврология и нейрохирургия детского возраста / В. М. Смирнов. - Л., 1976.

2. Марковская М. Ф. Дефектология / М. Ф. Марковская, В. В. Лебединский, К. С. Лебединская. - М., 1981.

3. Баллонов Л. Я. Психиатрия / Л. Я. Баллонов, В. Л. Деглин и др. — М., 1976.

4. Московичуте Л.И. Эндовазальная нейрохирургия / Л. И. Московичуте. - М., 1978.

5. Серёгин Ю. В. Способ лечения детских церебральных параличей и устройство для его осуществления : Авторское свидетельство СССР 839554 МКИ А 61 № 1 / 32 / Ю. В. Серёгин. $-1987$. 
6. Серёгин Ю.В. Психокоррекция речедвигательной функции у детей, страдающих детским церебральным параличом / Ю.В. Серёгин // Наука і освіта. Спецвипуск. - Одеса, 1997.

Аннотация. B статье представлена характеристика локально ограниченных поражений (ЛОП) головного мозга ребёнка, оказывающих решающее влияние на естественные процессы формирования и развития у детей высших психических функиий и, в частности, у тех из них, которые страдают детским иеребральным параличом (ДЦП).

Рассматривается и анализируется комплексный поход к реабилитащии детей, страдающих ДЦП, основанный на использовании адаптированных невролого-психологических методиках воздействия на психику ребёнка и его нервную систему.

Даётся краткая клиническая характеристика речевых расстройств и их типов, а также описывается психокоррекционная работа с детьми, страдающими ДЦП.

Ключевые слова: головной мозг, высшие психические функиии, локально-органические поражения головного мозга, психокоррекция, компенсаторные механизмы.

Abstracts. The article presents the characteristics of the child's local organic brain lesions, that has a decisive influence on the natural processes of formation and development of the children of higher mental functions and, in fairness, those of them who suffer from cerebral palsy (CP).

Reviewing and analyzing a comprehensive approach to the rehabilitation of the children, suffer from cerebral palsy, based on the use of adapted neuropsychological methods of influence on the psyche of the child and his nervous system.

A brief clinical characteristics of the speech disorders and their types, and describes psycho-correctional work with children, suffering from cerebral palsy.

Keywords: brain, higher mental functions, locally organic brain damage, psychological correction, compensatory mechanisms. 